\title{
Pedagogia da Práxis e as tecnologias: um caminho para o ensino da Física
}

\section{Práxis of education and the technologies: always for the Physic's teaching}

\author{
Vera Lucia Lavrado Cupello Cajazeiras ${ }^{1}$ \\ Cristina Novikoff ${ }^{2}$
}

Artigo
Original

Original

Paper

Recebido em 11/2011

\section{Palavras-chave: \\ Ensino de Física \\ pedagogia da Práxis}

Tics

\section{Resumo:}

Este artigo apresenta reflexões sobre uma proposta de ensino de Física, sob o conceito de educação para cidadania, mediada por tecnologias, em especial vídeos e animações. Para tal, nos apoiamos na legislação que rege o ensino no Brasil e suas orientações; na pedagogia da Práxis de Gadotti (2004-2006); e nas experiências de ensino e aprendizagem inovadores com tecnologias (MORAN, 2000). Como sustentação da proposta, foram elaboradas aulas na perspectiva da práxis pedagógica, com utilização de vídeos e animações. Trabalhamos com alunos da $1^{\mathrm{a}}$ série de uma escola estadual de ensino médio, localizada no Rio de Janeiro. A proposta propiciou um diálogo entre a experiência prática e a construção do conhecimento.

\section{Abstract}

This article presents some reflections on a proposal for Physics teaching, under the concept of education for citizenship, mediated by technology, especially videos and animations. To this end, we rely on the laws governing education in Brazil and its guidelines, the pedagogy of praxis by Gadotti (2004-2006), and the experiences of innovative teaching and learning with technologies (Moran, 2000). To support the proposal, classes have been prepared from the perspective of pedagogical praxis, using videos and animations. We worked with first grade students at a public high school, in the city of Rio de Janeiro. The proposal provided a dialogue between practical experience and knowledge building.

\section{Key words:}

Physics teaching

pedagogy of praxis

Tics

1. Mestranda em Ensino das Ciências na Educação Básica - UNIGRANRIO 


\section{Introdução}

Um dos eixos norteadores dos Parâmetros Curriculares Nacionais (PCNs) é o fortalecimento da educação básica - compreendendo educação infantil, ensino fundamental e ensino médio (BRASIL, 1996) - voltada para a cidadania, como uma das formas de contribuir para a melhoria da qualidade do ensino.

Esse é o caminho preconizado pela Lei de Diretrizes e Bases da Educação Nacional e objetivado nos PCNs: uma educação escolar que assegure ao educando a formação indispensável para o exercício da cidadania, além da qualificação para o trabalho e para a continuidade dos estudos (BRASIL, 1996).

Para percorrer tal caminho, apresentamos alguns pontos de reflexão sobre a Pedagogia da Práxis de Gadotti (2004), mediada pelas novas tecnologias, que nos darão o suporte teórico necessário para uma aprendizagem significativa e crítica, que acreditamos ser a marca de uma escola engajada na construção do conceito de cidadania.

O modelo de escola que nos interessa é afinado com o pensamento de Gadotti (2004) que, em suas análises, aponta para uma educação voltada para o desenvolvimento do espírito científico dos alunos, consideradas suas circunstâncias socioculturais

Para tanto, o educador deve estar atento ao contexto histórico-social em constante transformação em que se encontra, para unir, no seu fazer pedagógico, o quê ensinar, como ensinar, para quê ensinar e para quem ensinar. Será preciso uma nova postura dos professores na condução da sua prática pedagógica e da aprendizagem dos seus alunos, além da busca constante de novas formas didáticas e metodológicas que favoreçam o processo ensino-aprendizagem.

A era da informação vem transformando a maneira como a sociedade se organiza, portanto, a escola não pode ignorar as tecnologias de informação e de comunicação. A utilização dessas tecnologias não pode, e nem poderia, ficar de fora do ambiente da escola, de novos caminhos para a educação escolar e da renovação das tradicionais práticas docentes.

Nesse novo contexto, a escola continua sendo um dos principais canais de acesso às necessidades básicas de aprendizagem, mesmo considerando outros veículos de formação como a televisão, a Internet e tantas outras tecnologias educacionais da era da informação.

A questão que se apresenta é: como integrar o ensino de Física com a questão da cidadania, de modo a despertar no aluno maior interesse pelo conhecimento?

O objetivo deste artigo é relatar uma experiência de prática pedagógica voltada para despertar o interesse do aluno pela Física e para contribuir para o desenvolvimento do senso crítico e científico no ensino médio.

\section{Pedagogia da Práxis}

Na perspectiva da Pedagogia da Práxis (GADOTTI, 2004) a escola visa à humanização. A educação não se limita ao espaço da escola, há uma preocupação com a cultura em geral e não uma simples transmissão de conteúdos preestabelecidos. Seu principal objetivo é formar cidadãos no sentido real da palavra, capazes de questionar, refletir e criar. O professor não pode ser neutro, seu papel, enquanto agente de transformação, é político: cabe a ele buscar o porquê e o para quê educar. O aluno participa da construção de seu conhecimento. É a partir do desenvolvimento de uma capacidade de pensarem criticamente e de serem instrumentalizados com ferramentas adequadas para a transformação, e não apenas para assimilação e perpetuação das condições de vida existentes, que os alunos-cidadãos serão capazes de conquistar igualdade de oportunidades no mercado de trabalho do século XXI. Esse caminho faz parte do esforço para melhorar a educação no Brasil.

\section{A Educação e as tecnologias da informação e comunicação}

A formação para a cidadania e as tecnologias são as novas exigências para a escola e para o professor apontadas nos PCNs (BRASIL, 2002).

Diante de um mundo em constante mudança ediante da velocidade com que as informações se deslocam e se acumulam, a escola não pode deixar de usar as novas tecnologias no ensino/aprendizagem, proporcionando assim uma melhor construção e democratização da informação e do conhecimento. 
A Internet, a maior rede social do mundo, o maior sistema global de interação de redes de computadores, democratiza a informação e traz grande avanço à educação. Pela facilidade de comunicação, de obtenção de informações, de realização de pesquisas, de atualização de notícias e eventos e, principalmente, de disseminação de todos os tipos de mídia (áudio, filmes, texto, imagens ao vivo, fotografias, músicas, dentre tantos outros), vem atraindo e conquistando cada vez mais jovens.

Entendemos que, na sociedade atual, a imagem é um dos instrumentos que mais sensibiliza os alunos. Por isso, dentre as várias opções tecnológicas, enfatizamos, em nossa proposta, a utilização de vídeos. Esse meio, como a TV, combina comunicação sensorial-sinestésica com a audiovisual; começa pelo sensorial, pelo emocional e pelo intuitivo, para atingir posteriormente o racional. Os vídeos facilitam a motivação, são dinâmicos, contam histórias e causam impacto.

$\mathrm{O}$ vídeo tem vantagens sobre a $\mathrm{TV}$, pois possibilita fazer pausas para reflexão, trabalhar recortes para se chegar à totalidade, trabalhar a linguagem escrita através das legendas, além de tornar mais próximo um assunto difícil, ilustrar um tema abstrato, tornar visíveis realidades distantes do cotidiano.

Hoje, temos uma variedade de opções:

- portais como o YouTube, que possibilitam acessar vídeos sobre vários assuntos;

- vídeoaulas, que trazem assuntos já organizados como conteúdo didático;

- vídeo de documentários - históricos e da atualidade;

- vídeo como produção individual ou coletiva - a produção de vídeos é importante para documentação, registro de eventos, de aulas, de estudo do meio, de experiências e entrevistas.

No artigo O vídeo na sala de aula, Moran (1995) afirma que:

As linguagens da TV e do vídeo respondem à sensibilidade dos jovens e da grande maioria da população adulta. São dinâmicas, dirigem-se antes à afetividade do que a razão. O jovem lê o que pode visualizar, precisa ver para compreender. Toda a sua fala é mais sensorial-visual do que racional e abstrata. Lê, vendo.
O uso de mídias e tecnologias nas salas de aula, hoje em dia, não é mais tido como fator diferencial e, sim, como necessidade da educação contemporânea. A incorporação das tecnologias na educação facilita o processo de ensino/aprendizagem, uma vez que possibilita a integração de vários recursos e suportes provenientes das diversas mídias e que podem ser acessados em tempos e espaços favoráveis a cada indivíduo.

O desafio do professor está em utilizar as tecnologias adequadamente, objetivando o processo educativo integral do aluno-cidadão. Para isso, não basta apenas adotar uma nova técnica de ensino, mas adotar novas metodologias pautadas em uma perspectiva crítica, ou seja, fazer uso dessas tecnologias na perspectiva da práxis educativa. Fazer uma educação da práxis é optar pelo coletivo, pela transformação, pela reflexão permanente e por uma re-construção diária da escola.

A escola na sociedade da informação tem papel de gestora da informação, construtora e reconstrutora de saberes e conhecimentos socialmente significativos; agregadora de pessoas, movimentos e organizações - uma escola científica e transformadora (GADOTTI, 2004).

\section{As tecnologias da informação e comunicação e o ensino de Física}

De acordo com os PCN's (2000, p.11-12):

As novas tecnologias da comunicação e da informação permeiam o cotidiano, independente do espaço físico, e criam necessidades de vida e convivência que precisam ser analisadas no espaço escolar. A televisão, o rádio, a informática, entre outras, fizeram com que os homens se aproximassem por imagens e sons de mundos antes inimagináveis. [...] Os sistemas tecnológicos, na sociedade contemporânea, fazem parte do mundo produtivo e da prática social de todos os cidadãos, exercendo um poder de onipresença, uma vez que criam formas de organização e transformação de processos e procedimentos. 
Diversas pesquisas na área educacional (BARBETA e YAMAMOTO, 2001 e 2002; CAMILETTI e FERRACIOLI, 2001; GUERRINI, 2002; MEDEIROS e MEDEIROS, 2002; ROSA, 1995 e 2000, entre outras) têm mostrado a eficácia da aplicação de métodos audiovisuais no ensino de Ciências. Essa tecnologia, hoje muito utilizada através de câmeras digitais e celulares, está ao alcance de professores e alunos. Possibilita a exploração de fenômenos e melhor compreensão conceitual. É um recurso que também pode ser aproveitado pelos alunos na realização de documentários, trabalhos de pesquisa, demonstrações experimentais entre outros.

No Brasil, foi a partir de 1990 que se deu a popularização e dinamização dos vídeos no processo de ensino/aprendizagem. Utilizar principalmente as tecnologias que trabalham com a linguagem audiovisual permite explorar ao máximo a discussão de conceitos físicos, facilitam a percepção da Física no cotidiano e favorecem discussões de temas em sala de aula de forma crítica, em consonância com a práxis pedagógica, visando a uma aprendizagem significativa.

Outro recurso muito utilizado no ensino de Física são as animações interativas, visto que muitos fenômenos físicos não podem ser visualizados nas aulas convencionais; é quase impossível, usando apenas giz e quadro negro, representar a dinâmica de um fenômeno físico como nos desenhos de uma animação.

A animação interativa facilita a representação e compreensão de conceitos abstratos através de objetos concretos, na medida em que torna possível a construção de sua imagem como uma realidade virtual.

O uso de animações contribui para motivar os alunos em tarefas com alto índice de interatividade, desenvolver habilidades de resolução de problemas, promover habilidades do raciocínio crítico, fomentar a compreensão mais profunda dos fenômenos físicos, acentuar a formação dos conceitos e promover a mudança conceitual na perspectiva de uma aprendizagem significativa, dentre outras (GADDIS, 2000 apud MEDEIROS e MEDEIROS, 2002, p.80)

Considerando-se a situação do ensino no País, especificamente o ensino de Física, torna-se fundamental procurar meios que permi- tam um melhor ensino/aprendizagem da disciplina, despertando o interesse do aluno pela Física e contribuindo para o desenvolvimento do senso crítico e cientifico no ensino médio da rede pública.

\section{A experimentação}

Uma questão que dificulta um ensino de Ciências voltado para formação de cidadãos conscientes e críticos é o distanciamento entre os conceitos científicos vistos na escola e as situações reais da vida cotidiana; no entanto, é importante buscarmos essa interação e mostrarmos como os conceitos científicos podem ajudar a compreender a realidade à volta da vida do aluno.

Nossa proposta foi trabalhar o conteúdo curricular de Física sugerido para o primeiro bimestre no $1^{\circ}$ ano do ensino médio, na perspectiva da práxis pedagógica, ou seja, preparar os alunos para compreender o papel da ciência na sociedade, pensar criticamente, resolver problemas, participar de debates e tomar decisões. Utilizamos alguns instrumentos tecnológicos (animações e vídeos do YouTube) como ferramenta pedagógica para desenvolver o projeto. A amostra envolveu uma turma do $1^{\circ}$ ano de uma escola estadual de ensino médio da cidade do Rio de Janeiro, do turno da tarde, formada por 27 alunos de 14 a 16 anos.

A experimentação - parte da dissertação Perspectivas da Pedagogia da Práxis no Ensino de Física - utilizou atividades com vídeos do cotidiano do aluno e animações para trabalhar os conceitos básicos de "calor" e "temperatura", fundamentais para a compreensão da Fisica Térmica. A metodologia consistiu na problematização do conteúdo em sala de aula e suas implicações na vida, favorecendo a construção do conhecimento de forma crítica e reflexiva. A essa concepção de ensino estabelecemos relações entre o conteúdo disciplinar e os extramuros (políticos, econômicos, sociais). Articulamos conhecimento geral e específico, de modo haver inter-relação entre teoria e prática, sujeito e objeto, parte e totalidade, conhecimento disciplinar e transdisciplinar. Por meio de uma relação dialógica, o aluno articulou os conhecimentos científicos com os saberes tácitos. 
A aula com este tipo de material despertou um maior interesse no aluno, promovendo um melhor convívio social, tanto com seus colegas quanto com seus professores.

Conforme Krasilchik e Marandino (2005, p.33), hoje, o ensino deve despertar o interesse dos alunos para conceitos fundamentais e verificar quais as suas ideias sobre o assunto em estudo, e, após os envolver em atividades de explicação dos fenômenos naturais, torná-los capazes de aplicar os conhecimentos adquiridos em novas situações.

Nesse sentido, neste experimento, partimos das concepções cotidianas que o aluno tem dos conceitos de calor e temperatura, para a partir daí traçar estratégias didáticas que favoreçam a aprendizagem.

Registramos aqui, que a ideia mais frequente dos alunos em relação ao conteúdo escolhido não corresponde ao conceito físico: "Calor está relacionado à temperatura alta". É importante ressaltar que as palavras, calor e temperatura, são usadas na linguagem cotidiana das pessoas, com significado diferente do significado científico, fato que atrapalha a compreensão do assunto. Utilizamos um vídeo do dia a dia do aluno, um noticiário da Rede Globo, "Rio, o segundo lugar mais quente do planeta", que trouxe informações sobre a temperatura do dia na cidade do Rio de Janeiro. Esse tipo de jornal, assistido por quase todos os alunos, propiciou mostrar que no cotidiano a linguagem utilizada não tem o mesmo significado da científica, mas que era importante o conhecimento para diferenciá-las.

Discutimos o conceito físico de temperatura, usando animações, que mostravam o que ocorre no interior de um corpo. Retomamos o que dissemos no início do artigo, sobre a importância da utilização da animação interativa no ensino de Ciências, pois facilita a representação e compreensão de conceitos abstratos.

Por meio desse recurso, o aluno pôde observar que as moléculas que formam um corpo estão em movimento constante e que o aumento de temperatura estava relacionado à agitação das moléculas que compõem os corpos. A animação mostra que à medida que a temperatura sobe, as moléculas se agitam mais. Desta forma, os alunos concluiram que a temperatura de um corpo estava relacionada com o nível de agitação molecular, pois quanto maior a agitação, maior a temperatura.
Para construir o conceito físico de calor, utilizamos um vídeo de um programa de culinária na TV. Selecionamos uma cena onde era colocada uma panela com 1 litro de água sobre a chama do fogão, por um determinado tempo. O objetivo central era constatar que a energia transferida para o sistema gerava tanto mudança de temperatura como mudança de fase (do líquido para o vapor), e que essa transferência de energia é denominada calor.

As atividades buscaram confrontar os conceitos cotidianos de calor e temperatura identificados numa reportagem de jornal, tão comum no verão carioca, e diferenciar essa ideia usada na linguagem cotidiana do conceito científico, discutido nas animações e nos vídeos.

Discutir questões como calor e temperatura; favorece estabelecer relações entre Física, meio ambiente e sociedade, não encerrando o conhecimento físico em conhecimentos técnicos e científicos. Nesse sentido, discutimos, a partir do conteúdo programado, um problema que vem afetando o planeta há muito tempo: o aquecimento global.

Utilizamos uma animação baseada no filme "Uma verdade inconveniente", um documentário de 2006 sobre mudanças climáticas, mais especificamente sobre o aquecimento global.

Essa atividade propiciou uma reflexão sobre o comportamento do ser humano em relação ao planeta, como a natureza responde e as consequências que esse comportamento vem trazendo para o planeta, sensibilizando os alunos em relação a questões ambientais. Percebemos, pelas falas dos alunos, que a atividade propiciou uma reflexão crítica sobre o tema, que vem ao encontro de nossa proposta, ou seja, uma educação voltada para formação de um espírito crítico por parte dos alunos, gerando aproximação entre ensino de Ciências e cidadania.

- "Cada ano que passa percebemos que a temperatura do planeta está aumentando, e as consequências disto são chuvas, ventos fortes, tsunami, etc."

- "É uma questão de conscientização; temos que diminuir o uso de combustíveis como a gasolina, diminuir a quantidade de lixo que produzimos, pois o mesmo produz gás metano, e impedir o desmatamento e queimadas em florestas." 
- "Se cada um fizer sua parte já melhora um pouco a situação do planeta, como por exemplo: separar o lixo orgânico do inorgânico, andar a pé, de bicicleta ou de ônibus em vez de carro, plantar mais árvores, etc"

- "O discurso é bonito, mas ninguém anda de ônibus se tem a chance de andar de carro."

- "As pessoas só se preocupam quando acontece a desgraça."

\section{Conclusões}

No documento denominado Ciências Naturais e suas Tecnologias, os PCNs remetem para a necessidade de "rediscutir qual Física ensinar para possibilitar uma melhor compreensão do mundo e uma formação para a cidadania mais adequada", sinalizando com alguns aspectos que podem direcionar o ensino nessa área, enfatizando temas significativos para o educando e, em especial, para o desenvolvimento de competências e habilidades relativas à representação, comunicação, investigação, compreensão e contextualização sociocultural.

A escola deve ter como objetivo formar o indivíduo para raciocinar, atuar, transformar, participar de discussões, compreender as causas e razões dos fenômenos. Para isso, o professor deve promover debates, lançar desafios e aguçar no indivíduo o desejo de buscar explicações. Ao aluno, deve ser dada oportunidade de participar ativamente das aulas, expor ideias e apresentar sugestões para solução de problemas.

O desenvolvimento do trabalho nos trouxe subsídios para a análise deste estudo, feito no $1^{\circ}$ ano do ensino médio em uma escola da rede estadual do Rio de Janeiro. A utilização de instrumento tecnológico, apresentado nas aulas, tornou a sala de aula um ambiente estimulante para a aprendizagem, além de ter possibilitado melhor compreensão dos conceitos abordados. Neste experimento, destacamos a importân- cia de se valorizar o conhecimento prévio do aluno, o suporte da tecnologia, em especial a utilização de vídeos e animações, que aproximam o conteúdo de Física com a realidade social e cultural do aluno e os debates onde os alunos puderam compreender a cidadania como participação social e política, refletindo e posicionando-se de maneira crítica em relação a questões ambientais.

O conteúdo escolar passa a fazer sentido na medida em que ajudam a compreender o mundo, pois é através da compreensão dele que podemos refletir e intervir nos rumos em que caminha a sociedade, e através dessa prática exercer nossa cidadania.

Neste momento, em que o aquecimento global está na pauta, conhecer cientificamente os fenômenos que contribuem para o aquecimento global, e discuti-los, contribui para formação de indivíduos mais capazes de intervir.

Ensinar para a cidadania é propiciar ao aluno condições para construção de seu próprio conhecimento, fazendo suas próprias inferências, levantando hipóteses e tirando conclusões de forma independente, além de analisar e interpretar informações veiculadas através dos diversos meios de comunicação; é propiciar ao aluno condições de emitir juízo de valor sobre a questões que afetam a vida, como o trabalhado no experimento: aquecimento do planeta.

A melhoria da educação está estreitamente ligada à reelaboração da prática pedagógica, à reflexão e à incorporação dessa prática pelos docentes, o que aqui buscamos desenvolver.

Concluímos que o ensino de Física pela Pedagogia da Práxis, mediada por tecnologias audiovisuais, é um caminho para transformar as aulas num momento de interação e aprendizagem, problematizando o conteúdo, tornando-o interessante e instigando a curiosidade do aluno e que é viável de ser adotado em escola pública de ensino médio. 


\section{Referências Bibliográficas}

1. BARBETA, V. B.; YAMAMOTO, I. Simulações de Experiências como Ferramentas de Demonstração Virtual em Aulas de Teoria de Física. Revista Brasileira de Ensino de Física, São Paulo: FAPESP, vol 23, no. 2, jun. 2001, p. 215-225.

2. BRASIL. Lei 9.394. Lei de Diretrizes e Bases da Educação Nacional. Brasília, dez.1996.

3. BRASIL. Ministério da Educação. $P C N+$ Ensino Médio: Orientações Educacionais Complementares aos Parâmetros Curriculares Nacionais para o Ensino Médio. Ciências da Natureza, Matemática e suas tecnologias. Brasília: Ministério da Educação/Secretaria de Educação Média e Tecnológica, 2002.

4. CAMiletTI, G.; FERRACIOLI, L. $A$ utilização da Modelagem computacional Quantitativano Aprendizado Exploratório da Física. Caderno Catarinense de Ensino de Física. Santa Catarina: UFSC, vol. 18, no. 2, ago. 2001, p. 214-228.

5. GAdotTi, M. Pedagogia da Práxis: A Escola Como Projeto Sócio-Cultural. São Paulo: Cortez, 2004.
6. GUERRINI, I. M. et al. Utilizando Tecnologia Computacional na Análise Quantitativa de Movimentos: Uma Atividade para Alunos do Ensino Médio. Revista Brasileira de Ensino de Física, São Paulo: FAPESP, vol 24, no. 2, jun. 2002, p. 97-102.

7. MEC - Ministério da Educação; Parâmetros Curriculares Nacionais Ensino Médio; Brasília: MEC/Secretaria de Educação Básica, 2000.

8. MEDEIROS, A. e MEDEIROS, C. F. de. Possibilidades e limitações das Simulações Computacionais no Ensino da Física. Rev. Brasileira de Ensino de Física, São Paulo, v.24, n.2, p.77-86, jun.2002.

9. MORAN, J. M. O vídeo na Sala de Aula. Revista Comunicação e Educação, n.2, p.27-35. Editora Moderna, jan./abr. 1995.

10. ROSA, P. R. da S. O uso dos Recursos Audiovisuais e o Ensino de Ciências. Caderno Catarinense de Ensino de Física. Santa Catarina: UFSC, vol. 17, no. 1, abr 2000, p. 33-49. 